\title{
Why hide? Concealed sex in dominant Arabian babblers (Turdoides squamiceps) in the wild
}

\author{
Yitzchak Ben Mocha ${ }^{\mathrm{a}, \mathrm{b}, *}$, Roger Mundry ${ }^{\mathrm{c}}$, Simone Pika ${ }^{\mathrm{b}, \mathrm{d}}$ \\ a Max Planck Institute for Ornithology, Seewiesen, Germany \\ ${ }^{b}$ Department of Primatology, Max Planck Institute for Evolutionary Anthropology, Leipsig, Germany \\ ${ }^{\mathrm{c}}$ Max Planck Institute for Evolutionary Anthropology, Leipzig, Germany \\ ${ }^{\mathrm{d}}$ University of Osnabrück, Institute of Cognitive Science, Comparative Biocognition, Osnabrück, Germany
}

\section{A R T ICLE INFO}

Keywords

Arabian babbler

Birds

Concealed sex

Cooperatively breeding species

Human sexual behaviour

Tactical deception

Cooperation-Maintenance hypothesis

\begin{abstract}
A B S T R A C T
Striking uniformity exists in humans' preference to conceal sexual activity from conspecifics' view. Yet, little is known about the selective pressures acting upon its evolution. To investigate this question, we studied the cooperatively breeding Arabian babbler (Turdoides squamiceps), which has been suggested being the only other species where dominant individuals conceal sex regularly. We examined whether birds indeed conceal sex and tested different hypotheses postulating that sex concealment functions to avoid predators, signal dominance status, or to avoid social interference. The results showed that the birds concealed sex in all observed cases of copulation, did not prefer to copulate under shelters and concealed mating solicitations from adult conspecifics. In addition, subordinates did not attack dominants who courted the respective female. Hence, none of the tested hypotheses explains these results satisfactorily. We postulate that dominant Arabian babblers conceal sex to maintain cooperation with those helpers they prevent from mating. Empirical desiderata for testing this 'Cooperation-Maintenance' hypothesis are discussed.
\end{abstract}

\section{Introduction}

The diversity of cultures (Davenport, 1987) and mating systems (e.g., monogamy, polyandry; Schmitt, 2005) that have evolved in the human species (Homo sapiens) is manifold. Striking uniformity, however, exists in humans' preference for concealing sexual interactions from the view of other conspecifics (Ford \& Beach, 1951). For example, across cultures sexual activity occurs inside private dwellings (Ford \& Beach, 1951), away from the residential village (e.g., Yanomamö in Venezuela; Chagnon, 1997), or in the darkness of the night (e.g., Zapotec in Mexico; Taylor, 1979). Even married couples take active precautions to keep their sexual encounters private. Malekula couples from Melanesia, for instance, were reported to return home from the mating place in different directions (Deacon \& Wedgwood, 1934) and Mehinaku pairs in Brazil have intercourse in agreed secret locations (Gregor, 1985). If privacy cannot be achieved, couples often suppress their sexual activity (e.g., the agricultural culture in Melanesia; Davenport 1987). The preference to conceal sex has thus long been considered as a human universal (Friedl, 1994; MacCurdy, 1930; Symons, 1979; van Schaik, 2016), and even as a uniquely human trait (Diamond, 1992; Ford \& Beach, 1951). Furthermore, it has been speculated that concealed sex significantly influenced the evolution of humans' emotions (e.g., shame; MacCurdy, 1930) and sophisticated cognitive skills (e.g., modelling of social relations; Friedl, 1994).

In spite of almost a century of interest in humans' preference to conceal sex, the writing about the topic is anecdotic and scientific investigations are non-existent (Friedl, 1994; MacCurdy, 1930; van Schaik, 2016). Thus, the function fulfilled by this behaviour and the selective pressures driving its evolution remain unclear (Friedl, 1994; van Schaik, 2016). One reason for human couples to conceal sex is the preservation of social norms. For instance, individuals living in serial monogamous societies but engaging in extramarital sex conceal their sexual affairs to avoid being interrupted and to escape social punishment (Howie \& Pomiankowski, 2016; Schröder, 1993). However, the question of why humans conceal sexual interactions even when they are in socially accepted relationships (e.g., formalized partnerships, marriages) still remains a puzzle. Some scholars suggested that concealed sex in humans is a strategy to avoid overt reproductive competition (Friedl, 1994; MacCurdy, 1930; Suggs, 1966; Symons, 1979; van Schaik, 2016). This hypothesis however fails to explain why concealed sex evolved to be the norm in humans, but does not play a significant role in other animal species especially in our closest living relatives, the 
great apes (Ben Mocha and Pika, in preparation).

In the absence of systematic, quantitative studies and the ethical limitations of behavioural experiments on concealed sex in humans (Diamond, 1992), a cross-species comparative approach may shed important light on the selective pressures driving the evolution of this preference (van Schaik, 2016). In nonhuman species, elusive mating behaviour has been reported in a wide range of taxa, such as for instance carnivores (e.g., Helogale parvula: Creel, Creel, Wildt, \& Monfort, 1992; Crocuta crocuta: Kruuk, 1972), passerines (e.g., Prunella collaris: Davies, Hartley, Hatchwell, \& Langmore, 1996; Chiroxiphia linearis: McDonald \& Potts, 1994), primates (e.g., Ateles belzebuth chamek: Gibson, 2010; Theropithecus gelada: le Roux, Snyder-Mackler, Roberts. Beehner, \& Bergman, 2013), and ungulates (Ovis canadensis: Hogg, 1984). In these species, however, the use of concealed sex is mainly restricted to subordinate individuals and is only rarely been used by dominants (Ben Mocha and Pika, in preparation). In addition, in these species sexual interactions are often disrupted by conspecifics (Ber Mocha and Pika, in preparation). Thus, similarly to socially unaccepted couples in humans, subordinate animals may conceal sex to avoid harassment by conspecifics (Howie \& Pomiankowski, 2016; Niemeyer \& Anderson, 1983). Yet, why would dominant animals - defined here as individuals that are able to use their dominance to suppress interference - need to conceal sexual activity? Here, we argue that this question for nonhuman species is equivalent to the anthropological question about the motives of socially accepted human couples to conceal sex.

Regular concealed sex within dyads of dominant individuals has so far only been suggested by "preliminary observations" in a single nonhuman animal species - the cooperatively breeding Arabian babbler (Turdoides squamiceps) (Zahavi, 1988, 1990). Arabian babblers are passerine birds that live all year long in stable social groups of two to 20 individuals (Zahavi, 1989). Groups vary in their composition and show all combinations of age, sex and kin relations (Zahavi, 1989). The dominant pair produces $95 \%$ of the offspring (Lundy, Parker, \& Zahavi. 1998), but relies strongly on systematic alloparental care of other group members (e.g., by feeding the nestlings; Ostreiher, 1997; Ridley, 2007).

Arabian babblers are distantly related to humans in phylogenetic terms. Yet, similar behaviours may have evolved due to similar selection pressures (Emery \& Clayton, 2004). Consequently (and similar to other scientific fields trying to understand human evolution, e.g., lan guage evolution; Hauser, Chomsky, \& Fitch, 2002), investigations of behavioral phenomena due to convergent evolution are powerful tools to understand the factors driving the evolution of the behaviours in question. Thus, to shed light on the selective pressures that may have driven the evolution of concealed sex, we re-visited Zahavi's claim that dominant Arabian babblers regularly conceal sex from conspecifics (Zahavi, 1988). To achieve this goal, we studied the behaviour of a wild population of individually marked Arabian babblers living in the Shezaf Nature Reserve in Israel.

We addressed the following two questions: First, do Arabian babblers regularly conceal sex from conspecifics regardless of their dominance rank? To answer this question, we followed the approach by Overduin-de Vries, Spruijt, Vries, and Sterck (2015) and paid special attention to two behavioural strategies implicated with tactical deception: "using peripheral locations" (i.e., the pair increases its distance from bystanders to $>100 \mathrm{~m}$ ) and "hiding behind opaque objects" (i.e., both individuals position themselves on one side of an opaque object, while the audience is on the opposite side). If Arabian babblers conceal sex, we predicted that copulation attempts (defined here as "the female bends over by lowering her head and raising her tail, while the male mounts her") would be performed at times and/or in locations hidden from the view of other group members. Second, if Arabian babblers engage in concelaed sex, what is the function of this behaviour? Motives for con cealment of sex have not been studied intensively (Ben Mocha and Pika, in preparation). We therefore investigated the function fulfilled by this behaviour by testing three different hypotheses: First, the Predation
Table 1

Hypotheses previously suggested explaining concealed mating behaviour in different species and their predictions.

\begin{tabular}{|c|c|c|c|}
\hline Hypothesis & $\begin{array}{l}\text { Suggested for } \\
\text { (examples) }\end{array}$ & $\begin{array}{l}\text { Function of } \\
\text { concealed sex }\end{array}$ & Predictions \\
\hline $\begin{array}{l}\text { Predation } \\
\text { Hypothesis }\end{array}$ & $\begin{array}{l}\text { Humans (Homo } \\
\text { sapiens; MacCurdy, } \\
\text { 1930); } \\
\text { Richardson's ground } \\
\text { squirrels (Urocitellus } \\
\text { richardsoni; Davis, } \\
\text { 1982) }\end{array}$ & $\begin{array}{l}\text { To avoid } \\
\text { predation while } \\
\text { attention is } \\
\text { focused on } \\
\text { copulation. }\end{array}$ & $\begin{array}{l}\text { (a) Solicitation of } \\
\text { copulations would be } \\
\text { independent of conspecifics } \\
\text { presence; } \\
\text { (b) Copulations would occur } \\
\text { in sheltered locations. }\end{array}$ \\
\hline $\begin{array}{l}\text { Daminance } \\
\text { Signalling } \\
\text { Hypothesis }\end{array}$ & $\begin{array}{l}\text { Arabian babblers } \\
\text { (Turdoides } \\
\text { squamiceps; Zahavi } \\
\text { \& Zahavi, 1997) }\end{array}$ & $\begin{array}{l}\text { To signal } \\
\text { dominance over } \\
\text { other males by } \\
\text { deterring them } \\
\text { from interrupting } \\
\text { the privacy of } \\
\text { copulation. }\end{array}$ & $\begin{array}{l}\text { Dominants would solicit } \\
\text { copulations in the presence } \\
\text { of subordinates but not vice } \\
\text { versa. }\end{array}$ \\
\hline $\begin{array}{l}\text { Social } \\
\text { Interference } \\
\text { Hypothesis }\end{array}$ & $\begin{array}{l}\text { Humans (Suggs, } \\
\text { 1966); Dunnocks } \\
\text { (Prunella modularis; } \\
\text { Davies et al., 1996) }\end{array}$ & $\begin{array}{l}\text { To avoid physical } \\
\text { interference by } \\
\text { conspecifics. }\end{array}$ & $\begin{array}{l}\text { (a) Conspecifics would } \\
\text { respond with aggression to } \\
\text { others' mating: } \\
\text { (b) Solicitation of } \\
\text { copulations would not be } \\
\text { prolonged. }\end{array}$ \\
\hline
\end{tabular}

Hypothesis, which was proposed to explain the rarity of observed copulations in some species (Davis, 1982). Second, the Dominance Signalling Hypothesis that explicitly aimed to explain concealed sex in the Arabian babbler (Zahavi, 1988). Third, the Social Interference Hypothesis, which was postulated to explain concealed sex in species characterized by frequent interruptions of sexual interactions by conspecifics (Davies et al., 1996; see Table 1 for a summary of hypotheses and their predictions).

The "Predation Hypothesis",originally proposed to explain concealed sex in humans (Eibl-Eibesfeldt, 1989; MacCurdy, 1930), was subsequently applied to illuminate underground mating in several ground squirrel species (e.g., Urocitellus richardsonii, Davis, 1982; Michener, 2001). It postulates that interactants - with their attention being focused on the copulation itself - would preferentially mate in protected locations to avoid predation. If this hypothesis also applies to Arabian babblers, we predicted to find that solicitations of copulation would occur independently of conspecifics' presence. In addition, to ensure safety partners would copulate within shelters (that protect them from predator attacks) rather than in open arrays.

The "Dominance Signalling Hypothesis" (Zahavi, 1988, 1990; Zahavi \& Zahavi, 1997) postulates that Arabian babbler males conceal sex to signal their degree of dominance over other males in the group by deterring them from interrupting the privacy of copulations. The female, in turn, uses this information to "share her favors according to the relative importance of her partners" within the group (Zahavi \& Zahavi, 1997, p. 146). If Arabian babblers indeed conceal sex to signal their dominance, we predicted that dominant males would solicit copulations in the presence of subordinates. This would allow the females to reliably distinguish dominants, which initiate "private" copulation as a signal, from subordinates, which conceal solicitation of copulations to avoid harassment.

The "Social Interference Hypothesis" suggests that concealed sex occurs in species where group members aggressively interfere with conspecifics' mating attempts. Here, individuals actively seize opportunities when alone with their mating partners to solicit copulation. This hypothesis has predominantly been applied to explain concealed sex in a varietyof species such as, for instance, humans (Suggs, 1966), Rocky mountain bighorn sheep (Ovis canadensis; Hogg, 1988), and Dunnocks (Prunella modularis; Davies et al., 1996). If concealed sex in the Arabian babblers is used to avoid physical interference of group members, we predicted that sexual interactions would be accompanied by aggressive interventions of observers. In addition, to promote the completion of copulation, individuals would avoid prolonged communicative 
signalling to initiate copulations.

To test these hypotheses, we focused on episodes of "OBJECT PRESENTATION" ${ }^{1}$, a distinct gestural communicative behaviour often used by individuals of this bird species to solicit mating. It is defined as "an individual picking up an object with its beak, holding it in front of an opposite-sex conspecific and waiting for its response". We investigated (i) whether solicitations of copulations were concealed from conspecifics, (ii) whether the chosen mating location was protected from predators, (iii) whether dominant and subordinate individuals differed in their preference to conceal OBJECT PRESENTATIONS, (iv) the behavioura responses involved when a third party approaching the dyad during OBJECT PRESENTATIONS and/or copulation attempts, and (v) whether copulation attempts were initiated by OBJECT PRESENTATIONS.

\section{Materials and methods}

\subsection{Study site and population}

Data were collected within and at the fringe of the 'Shezaf Nature Reserve' $(30.718 \mathrm{~N} / 35.266 \mathrm{E})$ in Israel. A long-term study on the reserve's Arabian babbler population has been carried out since 1971, with birds being well habituated to human observers. Each bird was banded with a unique combination of four coloured rings, and the adult males and females could be reliably distinguished by the colour of their iris (Zahavi, 1989). The life history of all individuals, including their dominance ranks, has been recorded continuously (Ben Mocha, 2014; Zahavi, 1989). All individuals observed were sexually mature (older than one year of age) and all social groups consisted of a breeding pair and one to nine adult helpers (mean \pm SD of group size: $6 \pm 3$ ).

\subsection{Behavioural observations}

Data were collected during three breeding seasons (January-June 2010, August 2011-July 2012 and February-June 2014). Daily observations were carried out during the most active time of the birds (Dattner, 2005), i.e., in the first four hours after dawn when the group had left its roosting tree and during the two hours before dusk when the group returned to its roosting tree. The data collected in 2010 and 2012 are part of a larger study on social behaviour of Arabian babblers (Ben Mocha, 2014). They include opportunistic observations of OBJECT PRESENTATIONS $(n=8)$ and copulation attempts $(n=22)$. Data were documented via the study logbook and a series of still photos taken with a digital camera (Nikon D90; 4.5 frames per second) equipped with a telephoto lens (Nikkor $18.200 \mathrm{~mm}$ VR II). The data collection carried out in 2014 focused systematically on OBJECT PRESENTATIONS $(n=56)$ and copulation attempts $(n=34)$. It resulted in a total of $144.7 \mathrm{~h}$ of focal observations during 86 observation sessions. Behaviours were recorded from a distance of $2-20 \mathrm{~m}$ using a digital HighDefinition camera (Canon LEGRIA HFM 41) with an internal microphone. This method enabled the collection of high-quality footage combined with simultaneous observer comments of the respective behaviour (behaviour sampling rule, Martin \& Bateson 1994). After Arabian babblers have constructed their nest, an egg is laid each morning over three to six consecutive days and most copulations occur during this time (Perel, 1996; Zahavi, 1989). Hence, to document OBJECT PRESENTATIONS and copulation attempts, we followed the dominant females of the study groups during this egg-laying period. A Smartphone (Samsung Galaxy 2) with CyberTracker (CyberTracker) software was used to record the following data for each episode: (i) ID's of interactants', (ii) time of occurrence, (iii) whether the behaviours (OBJECT PRESENTATION/copulation attempt) were performed $>100 \mathrm{~m}$ away from the rest of the group or not, (iv) who moved away from whom before the copulation attempt (the group or the dyad), (v)

\footnotetext{
${ }^{1}$ From here one, the gesture object presentation is depicted in small capitals.
}

whether the behaviours took place within or behind thick vegetation that blocked visual contact between the dyad and the group, (vi) whether signallers of OBJECT PRESENTATION had actively guided recipients (distance of $>5 \mathrm{~m}$ ) to reposition themselves behind vegetation cover, (vii) the behavioural responses that occurred within $30 \mathrm{~min}$ after a third party approached the dyad during OBNECT PRESENTATION or a copulation attempt, (viii) whether or not a copulation was preceded by an OBJECT PRESENTATION, (ix) whether the copulation occurred within vegetation cover (e.g., acacia trees, Acacia; see videos S1 and S2) that could be regarded as a shelter from mammalian and aerial predators, and $(x)$ whether such a cover was available within $10 \mathrm{~m}$ of the actual location of the copulation.

\subsection{Statistical analyses}

Statistical analyses were conducted using the program $R$, version 3.3.3 (R Core Team, 2017) with the package Ime4 (version 1.1-13; Bates, Maechler, Bolker, \& Walker, 2015). All tests were two-tailed and the significance level was set to $\alpha=0.05$. Due to the elusive nature of the species' mating behaviour, data for some criteria were not always available. In these cases, we report a different sample size. Generalized Linear Mixed Models (GLMM) (Baayen, 2008) were used to account for pseudoreplication (Waller, Warmelink, Liebal, Micheletta, \& Slocombe, 2013). All models had a binomial error structure, logit link function (McCullagh \& Nelder, 1989) and included the signaller, recipient, dyad and social group identities as random intercept effects. The significance of each full model as compared to its corresponding null model (containing only the intercept and random effects; Forstmeier \& Schielzeth, 2011) was examined using a likelihood ratio test (R function "anova" with argument test "Chisq"; Barr, Levy, Scheepers, \& Tily, 2013; Dobson \& Barnett, 2008). We assessed the stability of each model by excluding each level of the random effects one at a time from the dataset and comparing model estimates derived from these data with the ones derived from the full data set. To keep type I error rate at the nominal level of $5 \%$ we checked which random slopes (Barr et al., 2013; Schielzeth \& Forstmeier, 2009) were identifiable, i.e., sufficiently varied within the levels of the random effects included in the respective model. This did not reveal identifiable random slopes to exist.

\subsubsection{Do Arabian babblers conceal copulation attempts and OBJECT} PRESENTATIONS from conspecifics?

We examined whether OBJECT PRESENTATIONS and copulation attempts were more likely than expected to occur when the group is away $(>100 \mathrm{~m})$. To do this, we analysed data for OBJECT PRESENTATIONS and copulation attempts in two separate GLMMs. The distance between the group and the dyad $(>100 \mathrm{~m} /<100 \mathrm{~m})$ was set as the response variable. The dominance rank of the signaller (dominant for alpha males and females/subordinate for other group members) was set as a fixed effect. We then bootstrapped $(n=1000) 95 \%$ confidence limits of the estimated probabilities of these behaviours to occur away from the group and compared them to the baseline proportion of time individuals were observed to be away from their group. To this end, during the breeding season of 2012 we continuously monitored whether there was at least one group member away $(>100 \mathrm{~m})$ from its group ( $\mathrm{n}=4$ social groups, 288 observation hours). Note that this is a conservative approach as most of the copulations documented in our study took place between the breeding pair, while here we estimated the percentage of time any other group member was absent. As previous studies also confirmed that Arabian babblers spend the majority of the day in close proximity to their group members (Dattner, 2005; Zahavi, 1988), we generalized this result from 2012 to the entire research period. Sample size for the copulation attempts model was 51 copulation attempts involving 16 signallers and 15 recipients forming 18 dyads from 11 groups. Sample size for the OBJECT PRESENTATION model was 63 OBJECT PRESENTATIONS involving 14 signallers and 14 recipients forming 16 dyads from 11 groups. 
In addition, we examined whether Arabian babblers use peripheral locations and hiding behind an opaque object as alternative strategies to conceal OBJECT PRESENTATIONS. To this end, we set a GLMM with the following response variable: an opaque object was located between the dyad and the group during an OBJECT PRESENTATION (no/yes). The signaller's dominance rank and whether the group was $>100 \mathrm{~m}$ away (yes/no) were set as fixed effects. Sample size for this model was 59 episodes that involved 13 signallers, 13 recipients forming 15 different dyads from 10 social groups.

\subsubsection{Do copulations occur in shelters protecting from predators?}

To examine whether Arabian babblers concealed sex in order to ensure safety from predation, we tested whether copulations were more likely to occur within vegetation cover when possible. We therefore confirmed that potential shelters were available within $10 \mathrm{~m}$ of all ac tual copulation sites. The GLMM included the protection of the copulation site (sheltered/not sheltered) as the response variable. We tested the probability of a copulation attempt to occur within a shelter by testing the intercept of the model after removing dominance rank (which appeared non-significant) by means of Wald's z-approximation (Field, 2005). Sample size was 56 copulation attempts that involved 16 signallers and 15 recipients forming 18 dyads from 11 social groups.

\subsubsection{Do conspecifics respond conspicuously or aggressively to others} mating behaviour?

To investigate whether Arabian babblers conceal sex to avoid physical interference, we documented any instance of these behaviours within $30 \mathrm{~min}$ of the appearance of a group member during others' performing an OBJECT PRESENTATION or a copulation attempt,

\section{Results}

\subsection{Do Arabian babblers conceal sex from conspecifics?}

A total of 56 copulation attempts in 18 different dyads was documented. The copulations involved 13 alpha females, seven alpha males $(n=41)$, and eight subordinate males $(n=15)$.

All documented episodes $(100 \%)$ were concealed from all other group members by at least one of the investigated strategies for tactical deception (see Fig. 1a): $73 \%$ of all observed copulation attempts occurred when the dyad was $>100 \mathrm{~m}$ away from its social group (i.e., concealment by using peripheral locations; $\mathrm{n}=51$ episodes). $87 \%$ of copulation attempts occurred behind or within vegetation (e.g., salt tree, Nitraria retusa) that prevented visual contact between the mating pair and its group (i.e., concealment by hiding behind an opaque object; $\mathrm{n}=55$ episodes).

Copulating dyads were not isolated from their groups because the latter simply moved further while the dyad engaged in prolonged courting. Rather in $84 \%$ of copulation attempts it was the dyad that had actively moved to conceal itself from other group members' view ( $n=43$ ): In six episodes, the dyad actively left its social group ( $>100 \mathrm{~m}$ ); in 17 episodes the signaller of OBJECT PRESENTATION lead the recipient a short distance $(5-50 \mathrm{~m})$ to copulate behind vegetation cover; and in 13 episodes the dyad flew $>100 \mathrm{~m}$ away from the group and later moved locally to position itself behind vegetation cover. In only seven episodes, the dyad had stayed behind while the group had moved $>100 \mathrm{~m}$ away from it, and it did not further reposition itself behind cover. Four out of these seven episodes were "opportunistic" copulation attempts of subordinate males with the dominant female (see result 3.4.2).

The probability of copulation attempts to occur away from the group was larger than expected given the proportion of time individuals were observed to stay away from their group during the breeding season (mean \pm SD: $11 \pm 8 \%$, range among groups: $3-22 \%$; Fig. 2).

\subsection{The predation hypothesis}

3.2.1. Does solicitation of copulations occur independent of conspecifics presence?

We recorded a total of 64 OBJECT PRESENTATIONS performed by six alpha males $(n=51)$, two alpha females $(n=3)$, and six subordinate males $(n=10)$.

One hundred percent of OBJECT PRESENTATIONS were concealed from all adult members of the group by using at least one of the strategies qualifying as tactical deception (Fig. 1b): Sixty-seven percent of all OBJECT PRESENTATIONS were produced when the group was away $(>100 \mathrm{~m})$ from the signaller $(n=64)$. Sixty-three percent of OBJECT PRESENTATIONS were performed after the signaller actively positioned itself behind an opaque object so that it was visible to the recipient only $(n=60)$. For instance, when the recipient was on top of a bush and the group foraged on one side of the bush, the signaller moved to the opposite side and signalled from there. We observed only two OBJECT PRESENTATIONS occurring in the presence of a group member. Both instances, however, involved a dependent fledgling $(<3$ months old $)$ as the audience and failed to elicit a response.

Similarly to copulation attempts, the proportion of OBJECT PRESENTATIONS produced away from the group was larger than expected given the proportion of time individuals were observed away from their group (11\%; Fig. 2). Furthermore, signallers used peripheral locations and hiding behind an opaque object as alternative strategies: OBJECT PRESENTATIONS tended to occur with a higher frequency from behind an opaque object when the group was nearby $(<100 \mathrm{~m})$ than when the group was $>100 \mathrm{~m}$ away (GLMM: $\chi^{2}<5.87, \mathrm{df}=1, \mathrm{P}=0.015$ Table 2).

\subsubsection{Do copulations occur in shelters protecting from predators?}

Travelling to shelters from predators (e.g., umbrella thorn acacia: Acacia tortilis) imposed no time or energetic costs as potential shelters were available within $<10 \mathrm{~m}$ of all 56 locations where copulation attempts occurred. Yet, only 29 copulation attempts took place within or under vegetation and there was no significant preference to copulate within shelters (test of the intercept: $0.08 \pm 0.3 ; \mathrm{P}=0.8$, see videos $\mathrm{S} 1$ and S2).

\subsection{The dominance signalling hypothesis}

3.3.1. Do dominant individuals solicit copulations in the presence of subordinates?

As presented above, dominant $(\mathrm{n}=54)$ and subordinate individuals ( $\mathrm{n}=10$ ) concealed $100 \%$ of their OBJECT PRESENTATIONS from adult group members. One of the two OBJECT PRESENTATIONS that occurred in the view of dependent fledglings was performed by a dominant male and the other by a subordinate male.

\subsection{The social interference hypothesis}

\subsubsection{Do conspecifics respond aggressively to others' mating behaviour?}

We observed nine OBJECT PRESENTATIONS and six copulation attempts in which other group members appeared during sexual interaction. An additional case involved the beta male observing the dominant pair copulating through a bush (see video S2). Out of these 16 episodes, nine involved subordinates appearing during an interaction between the alpha pair. Seven episodes involved the appearance of a higher-ranking male during an interaction between a lower-ranking male and the alpha female. In all 15 episodes in which the mating dyad noticed the third party, the dyad immediately dropped the object used for presentation and terminated its sexual behaviour. In only one episode, a beta male chased away the gamma male that attempted to copulate with the alpha female. Beside this exception, we did not observe any cases of physical aggression following these episodes. Dominance displays by alpha males were unidirectional towards subordinates that 


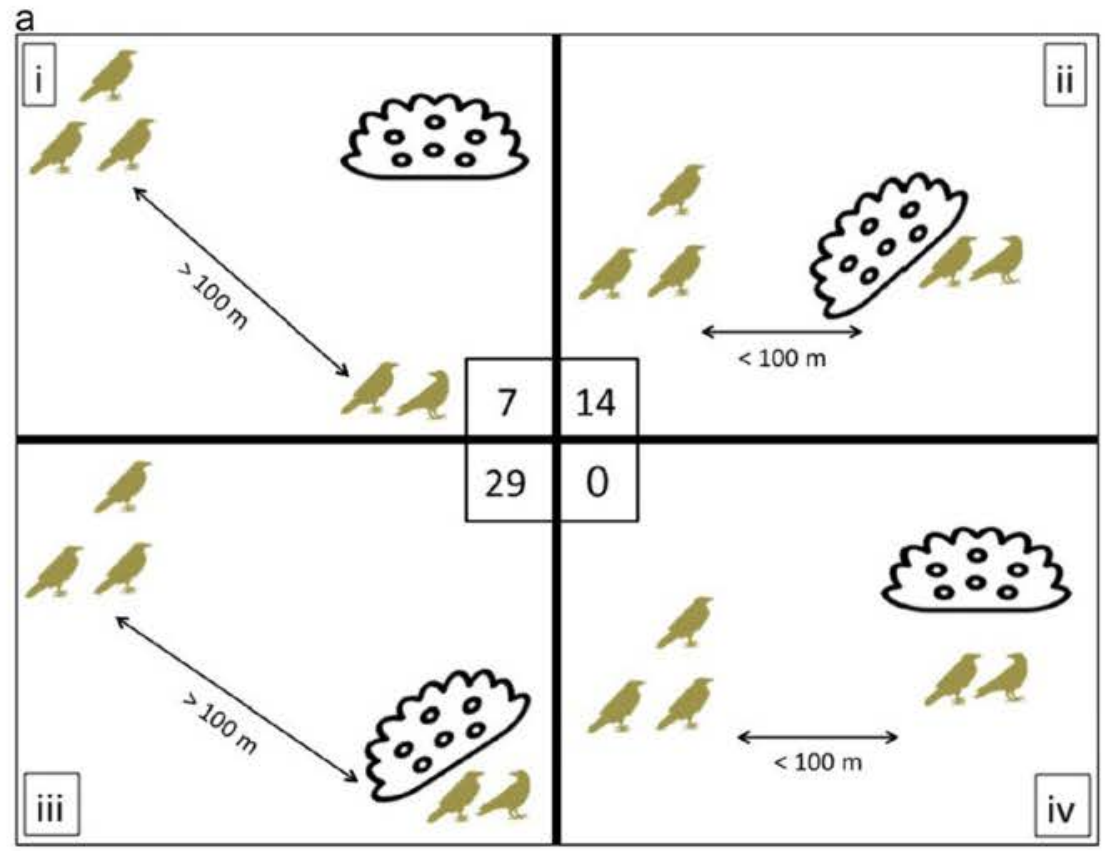

Fig. 1. Behavioural tactics used by Arabian babblers to conceal (a) copulation attempts and (b) solicitation of copulations. Depicted are the total numbers of observed episodes (in the centre) in which (a) copulation attempts and (b) solicitations of copulations occurred when the dyad was (i) $>100 \mathrm{~m}$ away from the group, but not behind an opaque object, (ii) $<100 \mathrm{~m}$ away from the group, but behind an opaque object, (iii) $>100 \mathrm{~m}$ away from the group and the dyad/signaller was behind an opaque object, and (iv) $<100 \mathrm{~m}$ away from the group and not behind an opaque object. Only episodes for which the distance and the location of the group were known are presented.

b

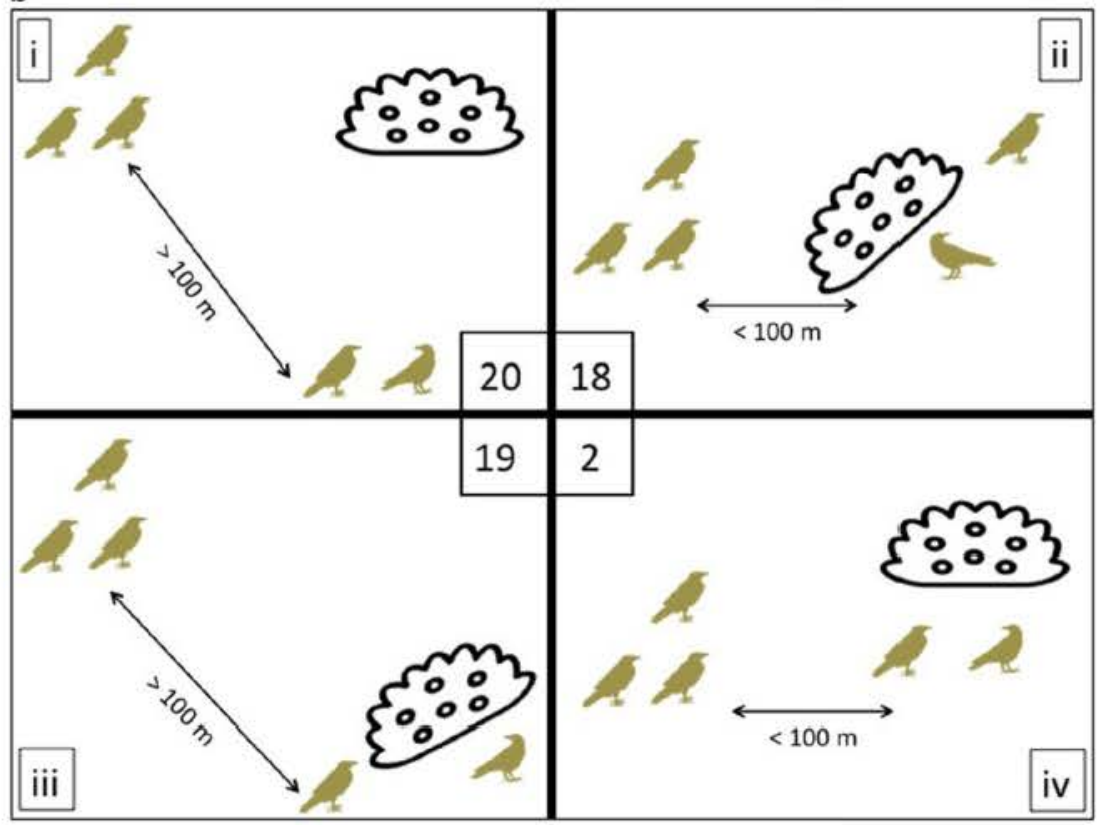

interrupted the privacy of OBJECT PRESENTATIONS and towards subordinates who courted the dominant female (see video $\mathrm{S} 3$ and Table S1 for description of all interactions).

3.4.2. Do individuals solicit copulations without prolonged communication? All copulation attempts by alpha individuals were initiated by OBJECT PRESENTATIONS $(\mathrm{n}=39$ ). However, about one third of subordinate males' copulation attempts were not initiated by OBJECT PRESENTATIONS (5 out of 14 episodes). All copulation attempts that were not solicited by OBJECT PRESENTATIONS had common characteristics: (i) They occurred after the alpha male suddenly left the proximity of the dyad (e.g., for chasing intruders); (ii) the dyad copulated immediately where it had been "left alone" by the dominant; and (iii) the female fully cooperated with the male by bending over for mating posture immediately. We did not identify prominent communicative signals that preceded these copulation attempts, but they may had been initiated by the female who first bended-over for copulation posture (see video S3).

\section{Discussion}

The present study aimed to provide insight into the selective pressures driving the evolution of concealed sex. We observed the sexual behaviour of Arabian babblers, which have been suggested as the only 


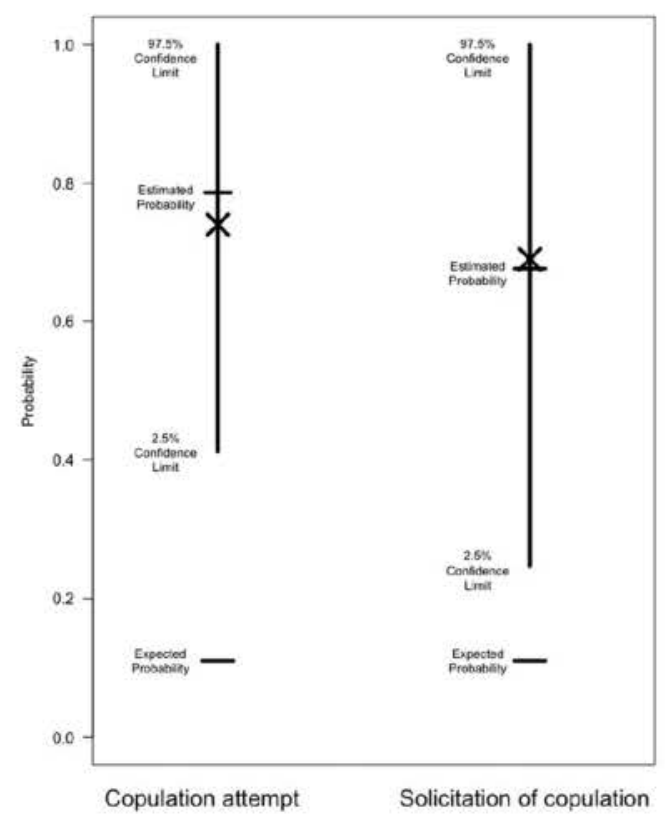

Fig. 2. Observed, expected and estimated probabilities of copulation attempts and solicitations of copulations to occur when the group was away from the dyad. $\mathrm{X}$ denotes the Observed Probabilities of copulation attempts and solicitations of copulations that occurred when the group was away $(>100 \mathrm{~m})$ from the dyad. The Expected Probabilities of copulation attempts and solicitations of copulations to occur when the group was away are based on the mean proportion of time when at least one individual was observed away from its group during the breeding season (11\%). The Estimated Probabilities and $95 \%$ Confidence Limits of copulation attempts and solicitations of copulations to occur when the group was away are based on a bootstrap analysis of GLMMs estimates.

\section{Table 2}

Factors influencing the probability of OBJECT PRESENTATIONS to occur behind opaque objects.

\begin{tabular}{llllll}
\hline Term & Estimate & SE & $\chi^{2}$ & df & $p$ \\
\hline Intercept & 2.210 & 0.971 & & & \\
Dominance rank of signaller (subordinate) & -0.472 & 1.260 & 0.136 & 1 & 0.712 \\
Group $>100 \mathrm{~m}$ away from signaller (yes) & -2.122 & 0.958 & 5.870 & 1 & 0.015
\end{tabular}

Generalized Linear Mixed Model based on 59 OBJECT PRESENTATIONS.

nonhuman animal species to regularly engage in concealed sex between dominant individuals (Zahavi, 1988). We addressed two research questions: First, do Arabian babblers regularly conceal sex from conspecifics regardless of their dominance rank? Second, if they do, what is the function of concealed sex in this species?

Overall, we found that (i) dominant and subordinate group members solicited copulations and attempted to copulate exclusively at times and/or in locations where they could not be seen by other adult members of their group; (ii) dyads did not show a preference to copulate within protected shelters; (iii) no physical aggression was shown when subordinates appeared during sexual interactions of the dominant dyad; (iv) higher ranking males responded with aggression and dominance displays to terminate lower-ranking males' mating behaviour; and (v) subordinates, but not dominants, regularly engaged in opportunistic copulations that were not solicited by OBJECT PRESENTATIONS.

The finding that all copulation attempts were concealed from adult group members provides the first systematic support for Zahavi's observations (Zahavi, 1988). These findings further show that Arabian babblers use two strategies in line with tactical deception to conceal their sexual activity: Using peripheral locations and hiding behind opaque objects (Overduin-de Vries et al., 2015). The cognitive abilities that underlie these behaviours should be further studied (e.g., whether Arabian babblers are able to discriminate their own visual perspective from that of the audience).

Concerning the function of concealed sex in Arabian babblers, we tested predictions resulting from three alternative hypotheses. Since solicitations for copulations did not occur independently of conspecific presence (Figs. 1b and 2) and copulations did not tend to occur within shelters from predators, we could rule out the Predation Hypothesis.

The results also did not support predictions for the Dominance Signalling Hypothesis - i.e., that dominant males solicit copulations in the presence of others to signal their dominance over subordinates - since dominants concealed all of their OBJECT PRESENTATIONS from adult group members.

We found that aggressive responses and dominance displays were only produced by dominants towards lower ranking individuals who engaged in sexual behaviour. In accordance with previous studies on our model species (Perel, 1996; Zahavi, 1988, 1990), subordinates were never observed to physically interrupt dominants' mating behaviours. Furthermore, only subordinate males were involved in opportunistic copulations that were not preceded by prolonged communication. These results support the predictions formulated for the Social Interference Hypothesis. However, they only satisfactorily explain the use of concealed sex by subordinate Arabian babblers.

We therefore argue that subordinate and dominant Arabian babblers may conceal sex for different purposes. Similarly to subordinate individuals in other nonhuman species (Ben Mocha and Pika, in preparation), subordinate Arabian babblers conceal sex to avoid physical interference by more dominant individuals. However, the findings that dominants (i) actively concealed mating behaviour from subordinate helpers, and (ii) terminated courtships when being observed by them, although not been interrupted physically, are in sharp contrast to the predictions made by all hypotheses tested. Hence, as a posteriori explanation, we postulate that concealed sex by dominant Arabian babblers fulfils a different and so far unrecognized function. As a proximate mechanism, concealed sex is used to prevent further social tension between group members. At the ultimate level, it functions to maintain cooperation and allopaternal care within the social group. While subordinate Arabian babblers provide crucial allopaternal care (Ridley, 2007), they are prohibited from mating (Perel, 1996), especially during the alpha female's fertile period (Lundy et al., 1998). Concealing triggers for social conflicts thus might reduce the chances of helpers dispersing or fighting with the alpha individuals over their breeder position - two results with a significant negative effect on the alpha pair's reproductive fitness (Keynan \& Ridley, 2016). Indeed, the breeding season of Arabian babblers is characterized by increased social tension between the dominant pair and their helpers (Dattner, 2005). Therefore, although the species' social system includes intense cooperative behaviours, it is also characterized by intense competitive interactions (Zahavi, 1990; Zahavi \& Zahavi, 1997). Individuals thus need to constantly balance and negotiate their social relationships, resulting in multifaceted nonaggressive strategies to avoid overt social tension and to maintain cooperation (c.g., allopreening: Dattner, 2005; allofeeding: Kalishov, Zahavi, \& Zahavi, 2005).

Key features of concealed sex have so far not been quantified in many species. We thus hope that this first report on regularly concealed sex by dominants in a nonhuman animal species will encourage more studies in other carefully selected model species. In particular, our study may be useful in shedding light on the evolutionary puzzle of concealed sex in humans. We propose that although concealed sex may fulfil different functions in different species (e.g., to avoid predation or social interruption), the phenomenon may also have evolved independently in distantly related species due to similar selection 
pressures. Specifically, we propose that concealed sex by dominant nonhuman animals and humans living in socially accepted relationships evolved as a function of two conflicting motives: (1) Some group members' mating are suppressed - at least with some specific individuals (for examples in humans see Daly, Wilson, \& Weghorst, 1982; for examples in nonhuman species see Young, Spong, \& Clutton-Brock, 2007); and (2) one's reproductive fitness depends on collaboration with those individuals whose mating behaviour is suppressed. This conflict characterizes the social system of Arabian babblers (Zahavi, 1989) but can also be found in many human societies. First, virtually all human societies are built upon social norms that allow sexual relationships among adults with specific partners only (e.g., through marriage Ford \& Beach, 1951). Thus although all members of a given society may have a sexual partner, sexual relationships with other community members are suppressed, with those breaking this social norm often receiving severe punishment (Daly et al., 1982). Second, at the same time, humans' fitness crucially depends on alloparental care provided by group members, which are often non kin at their reproductive age (Hill \& Hurtado, 2009; Hrdy, 2007; Quinlan \& Quinlan, 2008). We therefore suggest that concealed sex functions to maintain cooperation within societies of highly cooperative humans that, at the same time, restrict sex between specific partners only.

As for any post-hoc hypothesis postulated to explain the evolutionary origins of behaviour, our arguments are only as good as the amount of available comparative evidence (i.e., the number of species tested). We thus conclude with a brief set of empirical desiderata and hope that it will instigate more studies of this fascinating subject (and potentially falsify our claims). Our proposal is that concealed sex evolved to maintain cooperation when fitness strongly depends on cooperation with group members who are prevented from mating. The main prediction that follows is that dominant individuals will conceal sex in social systems that fulfil at least two conditions: First, mating is suppressed at least to some extent (e.g., with specific group members, during the fertility period of the female); and second, fitness dependency on cooperation. A third condition may be the presence of potential mates other than close kin in the social group. A next possible step to test this prediction will be to explore concealed sex in distantly related species that breed cooperatively and show monopolization of mating (e.g., Florida scrub jays, Aphelocoma coerulescens; Mumme, Bowman, Pruett, \& Fitzpatrick, 2015; pygmy marmosets, Cebuella pygmaea; Soini, 1987, 1988). In addition, since human societies show considerable variability in their degree of cooperation and sexual liberty in particular (Davenport, 1987), future studies should explore the cultural variation in the degree of sex concealment. Specifically, we predict that when dependency on cooperation is weaker or sexual liberty is higher, sexual privacy would be milder and vice versa (for potential examples see Crocker, 1990; Rival, 2016).

\section{Conclusions}

Here, we provide the first systematic evidence that dominant Arabian babblers regularly engage in concealed sex - a behaviour that has previously been suggested as a "human universal" (Friedl, 1994) and uniquely human (Diamond, 1992; Ford \& Beach, 1951). With regards to the function of this behaviour, we show that dominant Arabian babblers do not conceal sex to signal their dominance, to avoid predation, or to avoid physical interruption by subordinate group members. We suggest that concealed sex by humans and distantly related species such as the Arabian babblers evolved through convergent evolution triggered by the need to maintain intensive cooperation whilst suppressing collaborators' mating relationship within the social group. This called "Cooperation-Maintenance" hypothesis is the first to articulate testable predictions for the evolution of concealed sex in humans: Regularly concealed sex will occur in those animal species showing comparable level of mating monopolization and heavy reliance on cooperative support.
- Icons used in Fig. 1 were made by Freepik from www.flaticon.com

\section{Acknowledgements}

We are grateful to Amotz Zahavi and Avishag Zahavi for introducing us to the fascinating species of the Arabian babbler and for sharing their knowledge. We thank Yael Alon, Arnon Dattner, Oded Keynan, Dorit Narisna, Yonthan Narisna, Roni Ostreiher and Peter Santema for their invaluable assistance in the field, and Carel van Schaik for constructive and inspiring discussions. For their comments on earlier drafts and fruitful conversations, we thank Judith Burkart and Nora Gottlieb. We are indebted to Christophe Boesch for providing us with stimulating working facilities at the MPI EVAN. This project was supported by grants from the DAAD and the IMPRS for Organismal Biology to Y.B.M and a Sofja Kovalevskaja-Award of the Alexander von Humboldt Foundation (www.humboldt-foundation.de) to S.P.

\section{References}

Baayen, R. H. (2008). Analyzing linguistic data a practical introduction to statistics using $R$. Cambridge: Cambridge University Press.

Barr, D. J., Levy, R., Scheepers, C., \& Tily, H. J. (2013). Random effects structure for confirmatory hypothesis testing: Keep it maximal. Journal of Memory and Language, 68(3), 255-278. http://dx.doi.org/10.1016/j.jml.2012.11.001.

Bates, D., Maechler, M., Bolker, B., \& Walker, S. (2015). Fitting linear mixed-effects models using lme4. Journal of Statistical Software, 67(1), 1-48. http://dx.doi.org/10. $18637 /$ jss, v067,i01.

Ben Mocha, Y. (2014), The social and functional role of sentinel behavior in the Arabian babbler dominant Arabian babblers (Turdoides squamiceps). MSc thesis. Tel-Aviv University.

Ben Mocha, Y., \& Pika, S.. Why do humans and nonhuman animals conceal sex? The Cooperation-Maintenance hypothesis (in preparation).

Chagnon, N. (1997). In G. Spindler, \& L. Spong (Eds.). Yanomamö: Case studies in cultural anthropology(5th ed.). New York: Harcourt. http://dx.doi.org/10.1017/ CBO9781107415324.004,

Creel, S., Creel, N., Wildt, D. E., \& Monfort, S. L. (1992). Behavioural and endocrine mechanisms of reproductive suppression in Serengeti dwarf mongooses. Animal Behaviour, 43(2), 231-245, http://dx.doi.org/10.1016/\$0003-3472(05)80219-2.

Crocker, W. H. (1990). The canela (eastern timbira), I: An ethnographic introduction. VoL. 1. Washington, DC: Smithsonian Institution Press.

CyberTracker Retrieved January 29, 2015, from http://cybertracker.org/.

Daly, M., Wilson, M., \& Weghorst, S. J. (1982). Male sexual jealousy. Ethology and Sociobiology, 3, 11-27.

Dattner, A. (2005). Allopreening in the Arabian babbler (Turdoides squamiceps). MSc Thesis: Tel-Aviv University.

Davenport, W. H. (1987). An anthropological approach. In J. H. Geer, \& W. T. O'Donohue (Eds.). Theories of human sexuality (pp. 197-236). New York: Plenum Press.

Davies, N. B., Hartley, I. R., Hatchwell, B. J., \& Langmore, N. E. (1996). Female control of copulations to maximize male help: A comparison of polygynandrous alpine accentors, Prunella collaris, and dunnocks, P. modularis. Animal Behaviour, 51(1), 27-47. http://dx.doi.org/10.1006/anbe.1996.0003.

Davis, L. S. (1982). Copulatory behavior of Richardson's ground squirrels (Spermophilus richardsonii) in the wild. Canadian Journal of Zoology, 60, 2953-2955. http://dx.doi. org/10.1139/z82-373.

Deacon, B., \& Wedgwood, C. (1934). Malekula: A vanishing people in the new hebrides. London: George Routledge and Sons, Ltd. Retrieved from http://ehrafworldcultures. yale.edu/document $?$ id $=0012-004$.

Diamond, J. (1992). The third chimpanzee. On the evolution and future of the human animal. mond, J. (1992). The thind chim

Dobson, A. J., \& Bamett, A. (2008). An introduction to generalized linear models. CRC press. Eibl-Eibesfeldt, L. (1989). Human ethology. New York; Aldine de Gruyter.

Emery, N. J., \& Clayton, N. S. (2004). The mentality of crows: Convergent evolution of intelligence in corvids and apes. Science, 306(5703), 1903-1907. http://dx.doi.org/ 10.1126/science. 1098410.

Field, A. (2005). Discovering statistics using SPSS. Ism introducing statistical methods. Vol. 2. http://dx.doi.org/10.1016/j.landurbplan.2008.06.008.

Ford, C. S., \& Beach, F. A. (1951), Patterns of sexual behavior. London: Eyre \& Spottiswoode.

Forstmeier, W., \& Schielzeth, H. (2011). Cryptic multiple hypotheses testing in linear models: Overestimated effect sizes and the winner's curse. Behavioral Ecology and Sociobiology, 65(1), 47-55. http://dx.doi.org/10.1007/s00265-010-1038-5. 
Friedl, E. (1994). Sex the invisible. American Anthropologist, 96(4), 833-844.

Gibson, K. N. (2010). Male mating tactics in spider monkeys: Sneaking to compete. American Journal of Primatology, 72, 794-804. http://dx.doi.org/10.1002/ajp.20835.

Gregor, T. (1985). Anxious pleasures: The sexual lives of an Amazonian people. Chicago, Illinois; University of Chicago Press.

Hauser, M. D., Chomsky, N., \& Fitch, W. T. (2002). The faculty of language: What is it, who has it, and how did it evolve? Science, 298(2002), 1569-1579. http://dx.doi.org 10.1126 / science. 298.5598.1569.

Hill, K., \& Hurtado, A. M. (2009). Cooperative breeding in South American huntergatherers. Proceedings of the Royal Society B: Biological Sciences, 276, 3863-3870. http://dx.doi.org/10.1098/rspb.2009.1061.

Hogg, J. T. (1984). Mating in bighorn sheep: Multiple creative male strategies. Science, 225, 526-529. http://dx.doi.org/10.1126/science.6539948.

Hogg, J. T. (1988), Copulatory tactics in relation to sperm competition in Rocky Mountai bighom sheep. Behavioral Ecology and Sociobiology, 22, 49-59.

Howie, J., \& Pomiankowski, A. (2016). Female sneak copulation. Encyclopedia of evolutionary psychological science (pp. 1-5). . http://dx.doi.org/10.1007/978-3-319-16999. tionary 63 .

Hrdy, S. B, (2007). Evolutionary context of human development: The cooperative breeding model. In C. A. Salmon, \& T. K. Shackelford (Eds.). Family relationships: An evolutionary perspective (pp. 39-68). Oxford: Oxford University Press.

Kalishov, A., Zahavi, A., \& Zahavi, A. (2005). Allofeeding in Arabian babblers (Turdoides squamiceps). Journal of Ornithology, 146(2), 141-150. http://dx.doi.org/10.1007 s10336-005-0073-x,

Keynan, O., \& Ridley, A. R. (2016). Component, group and demographic Allee effects in a cooperatively breeding bird species, the Arabian babbler (Turdoides squamiceps). B, 182(1), 153-161. http://dx.doi.org/10.1007/s00442-016-3656-8.

Kruuk, H. (1972). The spotted hyena: A study of predation and social behavior. Vermont: Echo point books \& Media.

le Roux, A., Snyder-Mackler, N., Roberts, E. K., Beehner, J. C., \& Bergman, T. J. (2013) Evidence for tactical concealment in a wild primate. Nature Communications, 4, 1462 http://dx.doi,org/10.1038/ncomms2468.

Lundy, K. J., Parker, P. G., \& Zahavi, A. (1998). Reproduction by subordinates in cooperatively breeding Arabian babblers is uncommon but predictable. Behavioral Ecology and Sociobiology, 43, 173-180. http://dx.doi.org/10.1007/s002650050478,

MacCurdy, J. T. (1930). The biological significance of blushing and shame. British Journa of Psychology, 21(2), 174-182. http;//dx,doi.org/10.1111/j.2044-8295.1930. tb00584.x.

Martin, P., \& Bateson, P. (1994). Measuring behaviour: An introductory guide. Cambridge University Press.

McCullagh, P., \& Nelder, J. A. (1989). Generalized linear models. Metrika, 135. http://dx doi.org/10.1007/BF01894758.

McDonald, D. B., \& Potts, W. K. (1994). Cooperative display and relatedness among males in a lek-mating bird. Science, 266(5187), 1030-1032. http://dx.doi.org/10.1126/ science.7973654.

Michener, G. R. (2001), Great horned owl, Bubo virginianus predation on Richardson's ground squirrels Spermophilus richardsonii. The Canadian Field-Naturalist, 115(4), 543-548.

Mumme, R. L., Bowman, R., Pruett, M. S., \& Fitzpatrick, J. W. (2015). Natal territory size, group size, and body mass affect lifetime fitness in the cooperatively breeding Florid Scrub-jay. The Auk, 132(3), 634-646. http://dx.doi.org/10.1642/AUK-14-258.1.

Niemeyer, C. L., \& Anderson, J. R. (1983). Primate harassment of matings. Ethology and Sociobiology, 4(4), 205-220. http://dx.doi.org/10.1016/0162-3095(83)90010-9.

Ostreiher, R. (1997). Food division in the Arabian babbler nest: Adult choice or nestlin competition? Behavioral Ecology, 8(2), 233-238. http://dx.doi.org/10.1093/beheco 8.2.233.
Overduin-de Vries, A. M., Spruijt, B. M., de Vries, H., \& Sterck, E. H. M. (2015). Tactical deception to hide sexual behaviour: macaques use distance, not visibility. Behavioral Ecology and Sociobiology, 69(8), 1333-1342. http://dx.doi.org/10.1007/s00265-0151946-5.

Perel, J. (1996). Competition for breeding between Arabian babbler males. MSc thesis. Tel. Aviv University.

Quinlan, R. J., \& Quinlan, M. B. (2008). Human lactation, pair-bonds, and alloparents: cross-cultural analysis. vol. 19, 87-102, http://dx.doi.org/10.1007/s12110-007. 9026-9.

R Core Team (2017). R: A language and environment for statistical computing. Vienna, Austria: R Foundation for Statistical Computing. Retrieved from http://www.rproject.org/.

Ridley, A. R. (2007). Factors affecting offspring survival and development in a cooperative bird: social, maternal and environmental effects. Journal of Animal Ecology, 76(4), 750-760. http://dx.doi.org/10.1111/j.1365-2656.2007.01248.x.

Rival, L. M. (2016). Huaorani transformations in twenty-first-century Ecuador: Treks into the future of time. Tucson: University of Arizona Press.

Schielzeth, H., \& Forstmeier, W. (2009). Conclusions beyond support: Overconfident estimates in mixed models. Behavioral Ecology, 20(2), 416-420. http://dx.doi.org/10. 1093/beheco/arn1 145.

Schmitt, D. P. (2005). Sociosexuality from Argentina to Zimbabwe: A 48-nation study of sex, culture, and strategies of human mating. The Behavioral and Brain Sciences, 28(2), 247-275. discussion 275-311 https://dot.org/10.1017/S0140525X05000051.

Schröder, I. (1993). Concealed ovulation and clandestine copulation: A female contribution to human evolution. Ethology and Sociobiology, 14(6), 381-389. http://dx. doi.org/10.1016/0162-3095(93)90026-E.

Soini, P. (1987). Sociosexual behavior of a free-ranging Cebuella pygmaea (Callitrichidae, platymhini) troop during postpartum estrus of its reproductive female. American Journal of Primatology, 13(3), 223-230. http://dx.doi.org/10.1002/ajp.1350130302.

Soini, P. (1988). The pygmy marmoset, genus cebuella. In R. A. Mittermeier, A. Rylands, A. F. Coimbra-Filho, \& G. A. B. Fonseca (Vol. Eds.), The ecology and behavior of neotropical primates. Vol. II. The ecology and behavior of neotropical primates (pp. 79-129). Washington, DC: World Wildlife Fund.

Suggs, R. C. (1966). Marquesan sexual behavior. London: Constable and Company,

Symons, D. (1979). The evolution of human sexuality. New York: Oxford University Press.

Taylor, R. B. (1979), Teotilan Del Valle: A typical mesoamerican community, Ann Arbor: University Microfilms. Retrieved from hitt://ehrafworldcultures.yale.edu/ document?id $=$ nu44-011.\%0A.

van Schaik, C. P. (2016). The primate origins of human nature (1st ed.), New Jersey; John Wiley \& Sons.

Waller, B. M., Warmelink, L., Liebal, K., Micheletta, J., \& Slocombe, K. E. (2013). Pseudoreplication: A widespread problem in primate communication. Animal Behaviour, 86(2), 483-488. http://dx.doi.org/10.1016/j.anbehav.2013.05.038.

Young, A. J., Spong, G., \& Clutton-Brock, T. H. (2007). Subordinate male meerkats prospect for extra-group paternity: Alternative reproductive tactics in a cooperative mammal. Proceedings of the Royal Society B: Biological Sciences, 274(April), 1603-1609. http://dx.doi.org/10.1098/rspb,2007.0316.

Zahavi, A. (1988). Mate guarding in the Arabian babbler, a group-living songbird. Proceedings of the 19th international omithological congress (pp. 420-427). .

Zahavi, A. (1989). Arabian babbler. In I. Newton (Ed.). Lifetime reproduction in birds (pp. 253-275). London: Academic Press.

Zahavi, A. (1990). Arabian babblers: the quest for social status in a cooperative breeder. In P. B. Stacey, \& W. Koenig (Eds.). Cooperative breeding in birds: Long-term studies of ecology and behavior (pp. 103-130). Cambridge: Cambridge University Press.

Zahavi, A. \& Zahavi, A. (1997). The handicap principle: The missing piece of Darwin's puzzle, Oxford: Oxford University Press. 